\title{
Study on the New Teaching Reform Strategies of Automobile After-sales Service Course Project
}

\author{
Chen Haiyan \\ Nanchang Institute of Science \&Technology,Nanchang 330108,China
}

Keywords: Customer service, Curriculum reform, Teaching strategy, Innovation project, Excellent talents.

\begin{abstract}
In order to improve the teaching quality of automobile customer service course, new teaching strategy and explore new teaching strategies, this paper proposes a reform strategy based on project teaching, and proposes the customer service satisfaction evaluation teaching strategies of weighted evaluation method based on auto after-sales service evaluation. According to the occupational characteristics of automobile business course, we launch the new foundation education reform based on project modularization teaching, and break the traditional teaching mode according to the actual car after-sales service job experience and enterprise as the background. At the same time, to practice as the basis, to innovative projects and experimental base as the foundation, this paper carries out the new task and content, in order to achieve the auto after-sales service excellence talent training objective.
\end{abstract}

\section{Introduction}

Auto after-sales service curriculum project teaching reform is to cultivate outstanding talents plan as the goal, we must respect to students as the subject principles. In the implementation process of the whole project, we need to students' intrinsic interest as the main basis, to enable students to full participation in the project teaching and to leave space for creativity and decision for students [1-3]. The implementation of course reform needs to carry the students' knowledge ability, students' ability training, professional quality, professional ethics and career planning forming as the main teaching content, combined with business background and economic law, to improve the knowledge and ability of students' competition and cooperation aspect [4-6]. Through the implementation of the new teaching strategies, students need to do in learning, learning by doing, and then students learn the theoretical knowledge through practice and apply the theoretical knowledge into practice.

\section{Automotive After-sales Service Curriculum Development and Practice based on Project Teaching}

Through the automotive after-sales industry research and the automobile after-sales service job analysis, the automobile after-sales service mainly includes car insurance claims, after-sales reception and consultation, auto inspection and maintenance, auto maintenance, after-sales service maintenance work order formulation and a series of problems [7-9]. Thus, we try to break the original teaching concept, and we adjust the professional students' training program and implement the new teaching strategy [10-11]. In the implementation of the modular teaching plan, we strengthen students' awareness of after-sales service jobs, in order to make students more easily in the future work smooth induction, and to increase the students' second chance of promotion.

This study takes the customer's after sales service as the research object and develops the teaching content according to the automobile maintenance after sales service, and then we discuss the development process of curriculum content with businesses and schools' experts, analyzing the maintenance work order manufacturing process [12-14]. 


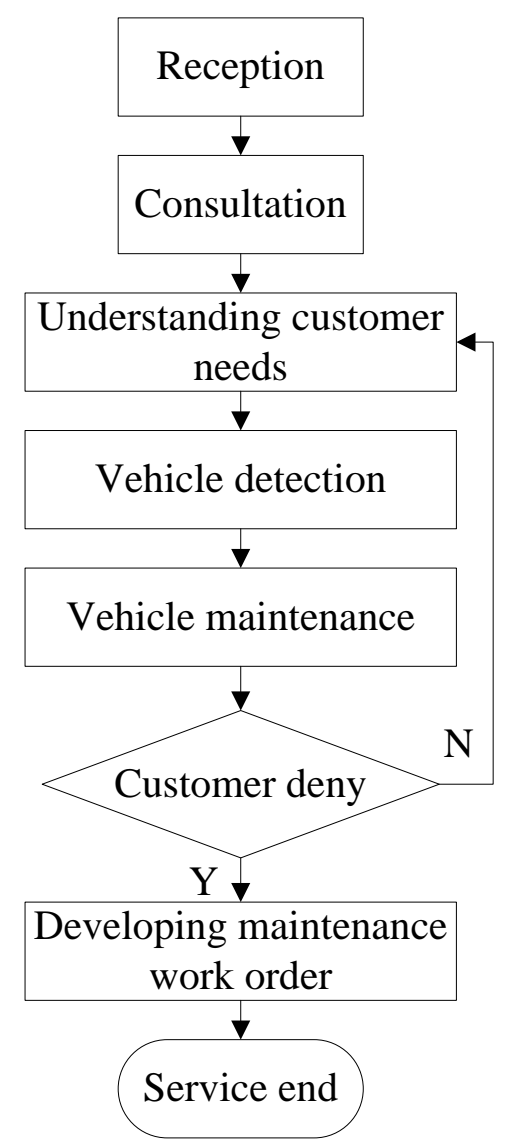

Fig. 1 Automotive aftermarket maintenance work order process

According to the specific process of the automotive aftermarket repair single formulation, we can determine the teaching knowledge goal, mastering the whole service process of the maintenance reception, mastering work specific aspects, mastering the basic knowledge of vehicle maintenance and mastering the concept of customer satisfaction. We need to understanding the basic etiquette of automotive after-sales service customer, understand the customer complaint handling principles and processes, master the reception and processing procedure of accident vehicle and understand the insurance company claims normal and program. At the same time, people have certain financial payment and invoice knowledge, understanding contract wine mad and other legal knowledge. In the second section, this paper will focus on after-sales service satisfaction as the basis, to discuss teaching strategies.

\section{The Teaching Strategy of After-sales Service Customer Satisfaction Evaluation System}

In order to provide more new teaching reference strategies for the automobile after-sales service program, this study establishes the evaluation model of after-sales service customer satisfaction, the main structural variables of evaluation model is the image [15-17]. Image contains seven structure variables, including satisfaction, customer complaints, perceived value, perceived quality, quality expectation, brand image and customer loyalty, in which the image as an exogenous variables, the other six variables as internal variables, the structure model is shown in Figure 2.

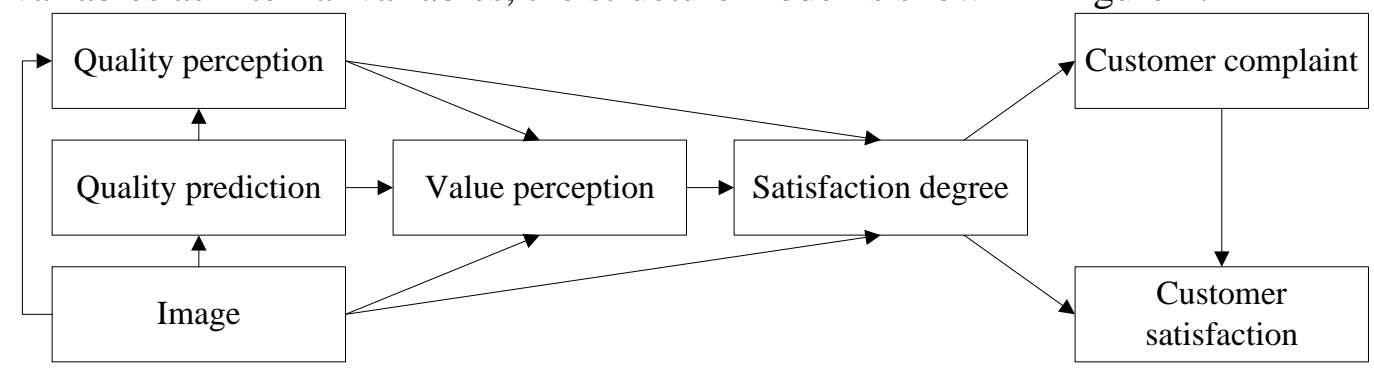

Fig. 2 Automobile after-sales service evaluation model 
Figure 2 shows the evaluation model of the automotive after-sales service, if people carry out accurate evaluation for automobile after-sales service, we require a combination of microscopic fields of customer satisfaction evaluation model, the model is multiplied by the estimated coefficients on the basis of the original service attributes, and then we can get the an overall satisfaction scores, for example, $A=\sum B_{i} W_{i}$, in which $B_{i}$ is the $i$-th attribute satisfaction; $W_{i}$ is the $i$-th weight, it can use the expert scoring weighting method to get the weight coefficient. The principles of expert scoring are that the most important is 5 , the least important is 1 , and the rest is 2-4. Assuming that there are $m$ experts on $n$ index evaluation, expert $i$ on the evaluation index weights is $w_{i 1}, w_{i 2}, \ldots, w_{i n}$, the statistical weighting is $W=\left(w_{1}, w_{2}, \ldots, w_{n}\right)^{T}$, in which $w_{j}=(j=1,2, \ldots, n)$ shows $m$ experts on the arithmetic average of $j$ index weight, and its expression is

$$
w_{j}=\frac{1}{m} \sum_{i=1}^{m} \rho_{i} w_{i j}
$$

So we can get the simplified weight calculating formula, and it is

$$
w_{i}=\frac{\sum_{j} w_{i j}}{\sum_{i} \sum_{j} w_{i j}}
$$

Wherein, $w_{i}$ shows the weight of the $i$-th evaluation content index, $w_{i j}$ shows the ordinal sort of the $j$-th experts on the $i$-th index. Through the expert weighting method, this paper carries out the index weight evaluation, in which all of its weight is 1 , the indicators of experts weights is shown in Table 1.

Table 1. Expert weighting index

\begin{tabular}{|c|c|c|c|c|c|}
\hline Evaluation project & \multicolumn{5}{|c|}{ Important degree } \\
\hline Reception service & 1 & 2 & 3 & 4 & 5 \\
\hline Consulting service & 1 & 2 & 3 & 4 & 5 \\
\hline Auto detection & 1 & 2 & 3 & 4 & 5 \\
\hline Car maintenance & 1 & 2 & 3 & 4 & 5 \\
\hline Car maintenance & 1 & 2 & 3 & 4 & 5 \\
\hline Make work order & 1 & 2 & 3 & 4 & 5 \\
\hline
\end{tabular}

Table 1 shows the index importance table of the expert reproduction, the customer satisfaction evaluation project of the auto after-sales service is divided into six according to the index division, in which we score on indicators according to the important degree, so as to get the weight coefficient of each assessment project.

\section{Auto After-sale Service Course Project Teaching Reform Strategy}

Project system based on customer satisfaction. In order to improve the quality of automobile after-sales service, we first need to consider to ensure customer satisfaction degree of after-sales service, and customer satisfaction plays a decisive role for the specific implementation of after-sales service [18,19]. In the previous section, we have established the evaluation model of customer satisfaction, so in the implementation reform strategy of auto after-sales service course project teaching, we can take customer satisfaction evaluation model as the basis, to carry out the implementation of the new teaching reform program and perfect after-sales service course project teaching [20-22]. In the specific implementation process of teaching, we can guide students to use the software method, establishing customer satisfaction evaluation software interface, and we put forward the new measures of automobile after sales service according to customer's opinion. 
Teaching situation design. In the important link of the teaching scene teaching design, teachers create teaching situation, they first need to consider the completion of teaching tasks and the realization of teaching goals. At the same time, teachers should design a variety of specific experience for each kind of situation type. In the creation of situation, teachers cannot again simple problem students as the basis to avoid missing a lot of teaching content, they need to let the students encounter all problems or may encounter problems in the internship process, to solve through new teaching strategies, so as to accumulate more post experience, this is also the connotation of the new teaching reform.

\section{Hardware and software resource allocation and innovation module.}

(1) Hardware resource allocation

Auto after-sales service project course must have the necessary resources to support, such as the basic space, vehicles, multimedia, DMS system etc., in which only hardware configuration reaches the specific requirements of teaching implementation, in order to ensure the smooth implementation of the project teaching. But only hardware resources is not enough, we need to consider the students' knowledge comprehensive mastery and application ability in the implementation process, therefore the electronic assembly parts can be introduced, these not only give students assembly and welding training, but also train students design, innovation and debugging capabilities.

(2) Curriculum practice innovation

In order to realize the innovation of after-sales service courses, students must complete 10 credits' extracurricular activities, and the school can organize special science and technology innovation group and provide the necessary funding and experimental site for the group. Every year can organize students to participate in the virtual instrument design competition, electronic design contest, mechanical innovation design competition and a series of national university science and technology competitions. Students can open the experimental site, completing the practice innovation and teamwork projects according to their own interests, to improve the practical ability of the curriculum innovation.

\section{Summary}

This study combines the new curriculum reform teaching practice of the automobile after-sales service, it completes the design of a kind of reform program based on project teaching, and this paper puts forward after-sales service customer satisfaction evaluation teaching strategies of a weighted evaluation method. This paper introduces the auto after-sales service curriculum development and practice based on project teaching, and then introduces the teaching plan of after-sales service customer satisfaction evaluation system, finally summarizes the implementation reform strategy of automobile after-sales service course project teaching. Through the design of situational teaching reform practice, we has made some achievements, but also know the hardships of curriculum development, we hope that people create excellent courses and training outstanding talents through their constant practice and exploration, to make its own contribution.

\section{References}

[1] Y.W. Ceng, G..R. Liu. Exploration on the construction of scientific practice teaching system under the background of the excellence program. China university teaching, 2014(7): 75-78.

[2] L. Song. Application of project oriented teaching in vocational computer basic courses. China modern educational equipment, 2013(11): 72-74.

[3] R. Dai, Y. Zhao. The research and practice of sensor course practice teaching innovative system. Laboratory research and exploration, 2014(6): 137-139.

[4] M.X. Yuan, Y. Shen, Q. Wang. The project teaching reform of mechanical equipment electrical control course under the engineering oriented. China modern educational equipment, 2013(11): 42-44. 
[5] Y. Huang. The task driven teaching reform and practice based on the work process systematic oriented. Traffic occupation education, 2014(2): 17-20.

[6] A.F. Zhang, X.F. Liu. Study on the implementation of outstanding engineer training program. Engineering education, 2014(4): 56-59.

[7] Y.S. Tian, W.H. Liu. The exploration and practice of comprehensive design experimental project construction. Experimental technology and management, 2012 (2): 126-129.

[8] C. Xiao. The exploration of the discipline competition system for outstanding engineers. Journal of Zhejiang University of Technology, 2014(2): 205-209.

[9] R.W. Wang. Chinese automobile brand customer satisfaction survey in 2005. City vehicles, 2015(5): 62-63.

[10] C.L. Wu. Analysis of using expert scoring method on debt value. China asset evaluation, 2015(11): 18-20.

[11] W.M. Zhang. The evaluation model of city sustainable development based on entropy method. Journal of Xiamen University, 2014(2): 110-116.

[12] X.J. Lan, L. Yao, S. Wu. Influence of automobile customer satisfaction factor analysis and index system. Shanghai car, 2015(9): 14-17.

[13] L.L. Li, B.Q. Ye. Establishment and evaluation model of customer satisfaction evaluation index system. Traffic science and technology, 2015(3): 78-80.

[14] J.X. You., X.M. Du, Y.J. Zhang. The customer satisfaction evaluation index system of of automobile industry supply chain. Industry engineering and management, 2014(1): 45-50.

[15] Y. Yang. Talk about the advantages and disadvantages of multimedia teaching in English teaching. Jilin radio and TV University, 2014(6): 146-147.

[16] Y.H. Zhang. Research on dynamic evaluation mode in College English network writing teaching. Foreign language, 2013(4): 73-81.

[17] X.Q. Wang. The advanced mathematics hierarchical teaching mode theory and practice. Jilin education, 2013, 21(11): 20-21.

[18] D.H. Mao. The implementation of higher vocational mathematic hierarchical teaching. Journal of Chongqing Vocational and Technical College, 2013, 16(4): 43- 44.

[19] B.P. Chen, A.L. Hu. Analysis of higher education popularization hierarchical teaching mode. Journal of Liaoning radio and TV University, 2013, 52(2): 5-52.

[20] F.Y. Li. The application and thinking of multimedia in English teaching. Chinese information technology education, 2014(8): 43-44.

[21] L.J. Song. Analysis of students' psychological characteristics in English teaching. Education exploration, 2014(3): 55-56.

[22] J. Song. English teaching should pay attention to the students' emotion. Chapter, 2013(5): 92-93. 